ISSN 2179-345X

Licenciado sob uma Licença Creative Commons

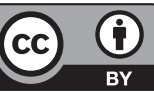

\title{
Desenvolvimento e tratamento especial e diferenciado na OMC: uma abordagem sob a perspectiva da doutrina do stare decisis - Parte I
}

\author{
Development and different treatment in WTO: \\ an approach from the perspective \\ of the doctrine of stare decisis - Part I
}

\section{Eduardo Saldanha}

Doutor em Direito pela Universidade de São Paulo (USP), professor de Graduação e Pós-Graduação do Centro Universitário Franciscano do Paraná (FAE), professor de Pós-Graduação da Universidade Estadual de Londrina (UEL), da Universidade do Vale do Itajaí (Univali) e da Pontifícia Universidade Católica do Paraná (PUCPR), Curitiba, PR - Brasil, e-mail: eduardo@mdss.com.br

\section{Resumo}

O tema comércio internacional e desenvolvimento sob a perspectiva do tratamento especial e diferenciado tem sido objeto de debates acalorados, principalmente no que diz respeito à efetividade das regras existentes no âmbito da Organização Mundial do Comércio (OMC). A revisão dos mecanismos de tratamento especial e diferenciado e diferenciação tem sido objeto de obstáculos negociais que têm impedido que tais instrumentos sejam aplicados de forma a proporcionar uma diminuição das diferenças de 
desenvolvimento dos membros da OMC. Uma das alternativas propostas é a possibilidade de utilização de precedentes vinculantes como mecanismos passíveis de permitir a adaptação das normas existentes, a fim de que estas se aproximem da realidade efetiva dos membros da OMC e respondam à problemática do desenvolvimento de forma mais específica.

Palavras-chave: Desenvolvimento. Tratamento diferenciado. Organização Mundial do Comércio.

\section{Abstract}

International trade and development from the perspective of special and differential treatment has been subject of strong debate, especially regarding the effectiveness of existing rules under the World Trade Organization (WTO). A review of mechanisms of special and differential treatment and differentiation has been object of bargaining obstacles that have prevented such instruments to be applied in order to allow a narrowing of development differences of WTO Members. An alternative option is the use of legally binding precedents, which could allow the necessary balance of existing rules in order to approximate the effective development reality of WTO Members and address development issues more specifically.

Keywords: Development. Different treatment. World Trade Organization.

\section{Introdução}

A discussão sobre a necessidade de um tratamento especial e diferenciado a países com graus de desenvolvimentos diversos no sistema internacional sempre teve grande relevância no comércio internacional. A construção do conceito de tratamento especial e diferenciado e os impactos da sua efetivação para o desenvolvimento dos países têm ocupado um espaço importante na definição de características do sistema multilateral de comércio internacional e nas teorias de desenvolvimento.

Há muito tempo chegou-se à conclusão de que um conjunto de normas multilaterais uniformes criador de obrigações idênticas a todos 
os participantes do sistema multilateral de comércio, independente do seu grau de desenvolvimento, traz mais prejuízos que benefícios, sendo a isonomia uma discussão que já poderia ter sido superada.

$\mathrm{O}$ atual debate sobre a aplicação de um tratamento especial e diferenciado já deveria ter superado a questão da isonomia no comércio internacional, pacificando seu entendimento de flexibilização quando se trata da relação comércio internacional e desenvolvimento. Tal superação é primordial no sentido de entender-se de uma vez por todas que realmente há a necessidade de um tratamento que encare os Estados-membros do sistema multilateral de comércio de acordo com o seu grau de desenvolvimento, ou seja, de forma diferenciada, flexibilizando o conceito de isonomia. Dessa forma, para estabelecer melhor a problematização do presente trabalho, parte-se da premissa da superação do debate sobre isonomia quanto à relação comércio internacional e desenvolvimento, estabelecendo-se a sua flexibilização.

O princípio da igualdade reavaliado, reestruturado, leva em consideração a existência de peculiaridades e diferenças econômicas, históricas, sociais, culturais, entre outras, dos Estados que fazem parte do sistema multilateral de comércio internacional, e conclui que não pode haver exigências idênticas a de Estados com diferenças tão profundas.

Entretanto, mesmo havendo vasta regulação de tratamento especial e diferenciado dentro do arcabouço normativo da Organização Mundial do Comércio (OMC), muitas vezes a sua efetivação, com vistas a reduzir a pobreza e como real instrumento de desenvolvimento, esbarra na determinação e diferenciação de graus de desenvolvimento entre os membros do sistema multilateral de comércio. Isso faz com que membros com graus de desenvolvimento e necessidades díspares sejam agraciados com um tratamento especial e diferenciado idêntico, gerando desvio de objetivos centrais da própria organização internacional e que conformam a base da criação dos mecanismos de tratamento especial e diferenciado.

$\mathrm{Na}$ busca por alternativas, algumas questões acabam se impondo, as quais serão brevemente discutidas neste trabalho, quais sejam elas: 
1) Como enquadrar diferenças fundamentais entre membros de um mesmo sistema de comércio multilateral considerando a necessidade de estabelecer um arcabouço normativo multilateral com o objetivo de promoção do desenvolvimento?

2) Quais os principais obstáculos do atual sistema de tratamento especial e diferenciado na sua consecução como mecanismo que não seja indutor de mais desigualdades?

3) Como administrar a questão de quais membros devem ter acesso a esse tratamento e quais os seus limites?

4) Como a atual estrutura institucional e legal da OMC pode ser utilizada na busca por maior efetividade das regras existentes e na definição de graus de desenvolvimento que estejam mais próximos às realidades dos Estados?

5) Para tanto, pode a doutrina do stare decisis surgir como uma alternativa a ser adotada na OMC?

Para tentar responder a tais questionamentos será necessária a análise de questões sensíveis ao sistema multilateral do comércio, como a regulação do comércio internacional e o objetivo de desenvolvimento; o histórico e o conceito do tratamento especial e diferenciado; os mecanismos existentes de diferenciação de graus de desenvolvimento; e a natureza jurídica do sistema legal da OMC, para que somente assim seja possível uma avaliação de alternativas.

\section{Comércio internacional e desenvolvimento}

A utilização do comércio internacional como instrumento pressupõe, primeiramente, que a sua gênese seja a promoção do ser humano com a efetivação de seu bem-estar. O Direito como heteronomia, limitador de condutas, pode e deve ser considerado como instrumento central na organização das relações comerciais internacionais na busca por desenvolvimento de forma sustentável. Contudo, o Direito de modo algum 
pode desconsiderar as diferenças fundamentais entre os atores desse processo de desenvolvimento, sob pena de obter resultados totalmente contrários à sua essência.

Dentro desse quadro, o tratamento especial e diferenciado cumpre uma função de extrema importância na instrumentalização do comércio internacional como vetor na promoção de desenvolvimento. Há que se considerar, entretanto, que a insuficiente regulamentação diante da necessidade de gerar obrigações diferenciadas aos atores do sistema multilateral de comércio transforma-se em obstáculo e não em engrenagem.

Assim, passa a ser central, além da análise dos instrumentos disponíveis ao sistema multilateral de comércio, a inserção destes nas dimensões particulares e contextualizadas do comércio internacional diante do desafio do desenvolvimento. Com base na definição de desenvolvimento como expansão das liberdades, quatro tipos de privações, ou não liberdades, são relevantes para a discussão de desenvolvimento perante o sistema multilateral de comércio.

Partindo da premissa de que privações podem resultar da impossibilidade de acesso a oportunidades econômicas e a consequências favoráveis disponibilizadas pelos mercados, um sistema multilateral de comércio que não promova um comércio justo em termos de igualdade de oportunidade priva o ser humano do acesso a oportunidades econômicas.

A habilidade de comercializar deve ser considerada como uma capacidade básica, pois a falta de elementos que sejam fundamentais ao bom desenvolvimento humano pode ser considerada, em termos gerais, como pobreza. Já que a pobreza não pode somente ser reconhecida em termos de baixa renda, a privação de uma capacidade básica de comercialização a partir de obstáculos à inserção no mercado pode marginalizar, o que certamente limita a liberdade de ação dos países diante do sistema.

Amartya Sen (2000) argumenta que negar aos indivíduos direitos civis fundamentais, como a oportunidade de participação efetiva em decisões cruciais referentes às questões manifestamente de interesse público, é negar o direito de desenvolver e reforçar os laços democráticos como parte essencial do processo de desenvolvimento. Para alcançar essa 
autonomia efetiva, o sistema multilateral deve primar pelo aumento da participação de todos os seus atores, para que assim seja dada oportunidade de participação política sobre as decisões que os afetam direta ou indiretamente. A melhora das condições de governança por meio de um sistema mais transparente e inclusivo aumenta a capacidade de participação de todos, grandes ou pequenos, fortes ou fracos, ricos ou pobres, expandindo a liberdade política.

Por sua vez, a regulação deve ter como objetivo permitir que os mercados trabalhem de forma mais eficaz em termos de desenvolvimento. Um sistema de regras baseado em políticas públicas e justiça social deve construir uma visão para o uso ótimo do mercado. Para que esse uso possa ser algo baseado na cooperação e expansão de liberdades, parece ser imperativa a necessidade de regras equilibradas, que visem a promover uma participação mais ampla e voltada ao desenvolvimento. Então, as regras que moldam o sistema multilateral devem ser transparentes e assegurar a promoção da igualdade a partir do reconhecimento das desigualdades.

O estabelecimento de regras que assegurem um equilíbrio justo entre custos e benefícios de um sistema de comércio aberto e a flexibilidade apropriada aos países em desenvolvimento de uma forma legítima e sustentável devem ser considerados como instrumento de expansão de liberdades e eliminação de privações, pois criam condições de participação mais efetiva e justa de todos os países inseridos no sistema multilateral de comércio.

Nesse contexto, o tratamento especial e diferenciado pode ser visto como um mecanismo para assegurar esse equilíbrio, considerando os diferentes níveis de desenvolvimento dos atores envolvidos. Portanto, o tratamento especial e diferenciado deve ser considerado em uma perspectiva consistente com a promoção de um comércio justo, construção de capacidades, boa governança e regras equilibradas na OMC.

Introduzir a dimensão do desenvolvimento no debate do comércio internacional contribui para a legitimidade do sistema multilateral e para a garantia das liberdades humanas, as quais, segundo Amartya Sen (2000), são as bases para o desenvolvimento. 


\section{Fair trade (comércio justo)}

Definir o que é comércio justo é uma tarefa árdua, o que não se buscará de forma exaustiva neste momento. Será, então, considerada a condição de construção de um comércio mais justo a partir da necessidade de expansão das liberdades dos atores do sistema multilateral de comércio. Isso ocorre principalmente no que diz respeito à oportunidade de participação nos benefícios apresentados pela liberalização comercial, transcendendo assim a perspectiva egoísta de ganhos individuais sem considerar o contexto das consequências das relações globais de comércio no que concerne à qualidade de vida.

A busca por um comércio justo, ou fair trade, parte do pressuposto de que os ganhos com a globalização e com o comércio internacional não são iguais, e que a balança da divisão de ganhos pende para o lado dos países desenvolvidos. Em um primeiro momento, pode-se dizer que isso se deve às enormes diferenças de poder econômico e níveis de desenvolvimento. No sistema multilateral de comércio, os países cooperam tendo por base um sistema, sendo a balança de divisão dos ganhos com o comércio internacional diretamente influenciada por essa estrutura normativa, a qual determina a forma de ação dos membros do sistema, e o espaço de atuação dos países dentro do sistema podendo refletir a concepção de justiça no comércio internacional.

Nesse caso, em um sistema que congrega necessidades diversas de atores distintos, as abordagens sobre justiça no comércio internacional não poderiam ser simples, como nos casos de acesso a mercados, subsídios agrícolas e práticas comerciais internas. As definições de quais resultados são justos mudam de país para país, dependendo das necessidades e níveis de desenvolvimento, pois a estrutura legal reflete diretamente nas políticas econômicas domésticas, as quais podem produzir consequências externas negativas.

Políticas domésticas claramente distorcem os mercados globais, mas antes de tudo deve-se considerar que essas políticas são efetivadas segundo uma estrutura legal, e é essa estrutura em um contexto multilateral que deve ser avaliada diante do conceito de justiça no comércio. 
Quando o sistema multilateral possibilita distorções comerciais que tornam desiguais as oportunidades de inserção e participação dos membros do sistema, este não promove justiça, mas sim priva atores desse cenário de participarem ativamente em igualdade de oportunidade, obstando assim as liberdades e, por conseguinte, o desenvolvimento.

A criação de normas ou a sua interpretação e aplicação no contexto do sistema multilateral de comércio, principalmente da OMC, deve considerar a participação de todos. Sendo assim, essa participação deve existir em igualdade de oportunidade em busca da remoção de distorções que afetem a distribuição dos ganhos com o comércio internacional, de forma a aumentar as liberdades internas nos Estados, expandindo o desenvolvimento individual ${ }^{1}$.

Removendo essas distorções e atingindo maior coerência nas políticas econômicas globais, principalmente quanto às políticas referentes a comércio e políticas de promoção de desenvolvimento, os países desenvolvidos podem contribuir de forma significativa, permitindo que as vantagens comparativas atuem. Uma política como essa estimularia o crescimento e aumentaria o bem-estar econômico internacional, tanto para os países desenvolvidos como para os países em desenvolvimento, possibilitando então um sistema baseado na concepção de justiça no comércio internacional (ISMAIL, 2005, p. 214).

Para Joseph Stiglitz e Andrew Charlton (2004, p. 11), para o alcance do comércio justo, qualquer acordo da OMC deve ser avaliado em termos do impacto ao desenvolvimento, e questões com impacto negativo no desenvolvimento devem ser retiradas da pauta de negociações, partindo do pressuposto de que as normas devem ser necessariamente justas.

Na verdade, deve-se transcender a simples avaliação, pois a real efetividade do Direito está na forma como ele é interpretado. Assim, não se trata

1 As políticas protecionistas dos países desenvolvidos na agricultura, por exemplo, são altamente distorcidas e impõem custos consideráveis aos produtores rurais dos países em desenvolvimento. Tais políticas pouco fizeram para corrigir as falhas de mercado e ainda aumentaram os danos ambientais a partir do encorajamento de técnicas produtivas cada vez mais intensivas.

Revista de Direito Econômico e Socioambiental, Curitiba, v. 3, n. 1, p. 11-42, jan./jun. 2012 
somente de uma questão de avaliação, mas sim de avaliação, interpretação e aplicação das normas existentes em consonância com os princípios normatizados e de acordo com a realidade internacional e de desenvolvimento.

Os acordos devem ser cuidadosamente criados, ou então interpretados quando já criados, sempre no sentido de promover desenvolvimento, e não proteger ortodoxias e interesses específicos de alguns grupos. Em outras palavras, a noção de comércio justo impõe a verificação de quais políticas e normas maximizam os ganhos para os países em desenvolvimento, devendo os resultados de liberalização agregar benefícios aos países mais pobres.

No sentido de desenvolvimento, a partir do estabelecimento de um sistema que possibilite a todos a oportunidade de participar dos benefícios da liberalização, Andrew Brown e Robert Stern (2007, p. 295) estabelecem que o alcance de um comércio justo tem duas características principais: igualdade de oportunidade e distribuição justa dos ganhos.

No caso da OMC, a igualdade de oportunidade deve sim ser vista como princípio moral, mas, além desse princípio, ela deve ser entendida como critério objetivo na construção de um sistema legal que realmente efetive juridicamente a oportunidade. Desse modo, todos poderiam ter acesso aos benefícios oferecidos pelo sistema multilateral de comércio, tornando-o mutuamente vantajoso, corrigindo as distorções e as desigualdades.

A OMC deve garantir que as políticas dos países desenvolvidos sejam consistentes com os seus objetivos em liberalizar os mercados internacionais, permitindo que as exportações dos países em desenvolvimento cresçam e se expandam. Para isso, o grande desafio para um comércio justo dentro da $\mathrm{OMC}$ é a diminuição da utilização de políticas de comércio distorcidas, principalmente no que diz respeito ao acesso a mercados e ao desenvolvimento.

O tratamento especial e diferenciado, como será visto posteriormente, pode ser utilizado como um instrumento interessante de aumento das oportunidades e ganhos mútuos no comércio internacional, desde que ele não traga medidas distorcidas subjacentes em razão da sua pouca especialização. 
Atualmente, a Cláusula da Nação Mais Favorecida e o Tratamento Nacional (artigos I e III do GATT), como base para a não discriminação, constituem regras basilares na busca por um comércio justo e bem distribuído. Contudo, de forma operacional, a aplicação rígida desses conceitos pode privar os atores da oportunidade de desfrutar da melhor forma possível do processo de liberalização, gerando desigualdades causadas pela simples impossibilidade de os países-membros participarem dos ganhos do comércio internacional de forma justa, tendo como obstáculos elementares as diferenças de poder e desenvolvimento.

A oportunidade de participação no comércio internacional deve induzir ganhos como consequência do uso desse sistema, e a justiça na distribuição desses ganhos gerados pelo comércio internacional significa a promoção de relações mutuamente vantajosas para os países com níveis de desenvolvimento diversos e características peculiares. Será somente significativo o equilíbrio na balança de benefícios advindos do acesso e uso do sistema multilateral do comércio se este permitir a aceleração do desenvolvimento, da expansão das liberdades humanas e da melhora na qualidade de vida, o que deve então nortear a avaliação de justiça no comércio internacional.

As medidas que possibilitam melhor distribuição dos ganhos no comércio internacional vêm do aumento das oportunidades e da busca por medidas que compreendam as condições especiais dos países em desenvolvimento e menos desenvolvidos. Modelos de acesso preferencial a mercados sem a necessidade de reciprocidade, como o SGP, têm sido um mecanismo usado na tentativa de melhorar a distribuição dos ganhos com o comércio internacional. A efetivação desses modelos está baseada em normas que compõem o sistema multilateral, e é por esse motivo que tais normas devem estar ligadas de forma bastante cuidadosa ao conceito de um comércio justo, que promova a igualdade de oportunidades em conjunto com a justa distribuição dos frutos advindos da utilização dos instrumentos colocados à disposição, tendo sempre como ponto de partida o reconhecimento das desigualdades. 
Todas essas questões acabam levando a alguns questionamentos, dentre eles: as normas existentes são suficientes para a promoção do desenvolvimento? A quem cabe a interpretação e a aplicação do Direito existente? A quem cabe a adaptação do Direito existente às novas realidades e necessidades da sociedade internacional?

\section{Capacidade de comercializar}

A expansão da liberdade é um fim prioritário e o principal instrumento para o desenvolvimento. Para Amartya Sen (2000), o desenvolvimento consiste na remoção de vários tipos de restrições que deixam pouca escolha e poucas oportunidades para o exercício de ações racionais.

Certas liberdades têm papel instrumental na promoção de liberdades de outras espécies. A liberdade econômica, por exemplo, pode ser complementada por oportunidades sociais de educação, o que estimula atividades no sentido de superar privações. O que se pode efetivamente realizar é influenciado pelas oportunidades econômicas, pelas liberdades políticas, pelos poderes sociais e condições individuais, como o acesso ao conhecimento e a possibilidade de utilização deste (SEN, 2000, p. 14).

Certamente, o simples aumento das oportunidades não faz com que os países em desenvolvimento, especialmente os mais marginalizados, aumentem a sua participação no comércio internacional e imediatamente se desenvolvam. É por isso que a expansão das liberdades deve ser entendida de forma coesa, sistêmica.

O sistema multilateral de comércio, para que possa ser considerado justo e indutor de desenvolvimento, deve ter igualdade de oportunidade e uma distribuição justa dos possíveis ganhos com o processo de liberalização. Contudo, para que isso aconteça, o acesso tem que ser realmente efetivo, pois a simples oferta de acesso a mercados não contribui automaticamente para um crescimento orientado às exportações. 


\section{Necessidade de regras equilibradas}

A globalização e a liberalização do comércio levaram a um aumento no fluxo de comércio. A partir da segunda metade do século XX, notou-se um incremento na regulação das transações comerciais mundiais, principalmente em virtude dos arranjos pós-Segunda Guerra Mundial, que levaram à criação do Banco Mundial, do Fundo Monetário Internacional e à assinatura do Acordo Geral de Tarifas e Comércio (GATT).

A partir desse momento, por mais que aparente uma forma tímida se comparada com os avanços da $\mathrm{OMC}$ em termos de regulação internacional do comércio, a configuração normativa aumenta a sua importância como instrumento de um processo de liberalização, assim como mecanismo importante na busca por desenvolvimento.

Um dos temas que, desde então, povoam as discussões acerca do sistema regulatório de comércio multilateral é o equilíbrio dessas regras no sentido de congregar os anseios e aspirações de todos os participantes. Tal princípio pode ser interpretado do corpo normativo da Organização Mundial do Comércio, o que por si só impõe uma interpretação e aplicação equilibrada das regras, mas na prática não é isso que se tem verificado.

Graças à configuração voluntarista, e também normativa, do Direito Internacional Público, o reflexo das normas internacionais no âmbito interno dos países também passa a aumentar, o que leva à busca por uma harmonia entre os sistemas doméstico e internacional. Os impactos das normas internacionais no âmbito interno, e vice-versa, exigem cada vez mais um maior equilíbrio entre compromissos internacionais e necessidades domésticas.

Existe, portanto, uma regulação de mercado em nível nacional para assegurar justiça social, ao mesmo tempo em que os fluxos internacionais requerem uma regulação para proteger o meio ambiente, a saúde humana e animal e os pobres de riscos sistêmicos, interesses muitas vezes não encontrados em todos os atores do sistema. O sistema multilateral de 
comércio está, então, posicionado no meio dessa dualidade normativa de congregar objetivos multilaterais com necessidades domésticas.

Por sua vez, a legitimidade de qualquer norma deve estar baseada na forma como ela congrega os anseios da sociedade com a limitação e determinação das ações dos destinatários da estrutura legal criada. Por isso, a formulação de comandos equilibrados com o alcance dos objetivos sociais tem como uma de suas bases o reconhecimento das diferenças intrínsecas aos atores do sistema, sendo esse reconhecimento condição essencial para a legitimação de uma estrutura normativa direcionada à realização humana e que permita a todos aproveitarem igualmente as oportunidades econômicas criadas.

No entanto, se depender dos anseios individuais dos membros do sistema, nem sempre serão alcançados os objetivos previstos nos acordos internacionais, vez que o conflito entre necessidades domésticas imediatas e concessões internacionais com resultados a longo prazo sempre será um elemento importante na negociação de acordos internacionais, o que certamente deve ser sempre levado em consideração.

Para isso, deve-se levar em consideração o seguinte questionamento: como equilibrar a legitimidade de um sistema normativo com a necessidade de normas eficazes, porém flexíveis? Como preencher as lacunas das normas sem desrespeitar o sistema multilateral, os acordos anteriormente e livremente concluídos? Quem tem legitimidade para tanto?

Se as normas de comércio, assim como sua interpretação e aplicação, não forem equilibradas, consistentes e dotadas de previsibilidade, elas certamente sofrerão com a falta de legitimidade. Isso pode ser alcançado se as regras reconhecerem que os interesses dos países desenvolvidos e em desenvolvimento podem não convergir totalmente, o que sugere que devem existir mecanismos que assegurem uma avaliação cuidadosa sobre o impacto de novas regras, ou de regras já existentes, para que a análise dos custos e benefícios dos compromissos assumidos possa ser a mais transparente possível. Esse mecanismo é importante para fornecer a base para uma maior flexibilidade na implementação de compromissos 
e para permitir que, caso esteja faltando capacidade técnica, possa ser implementada a assistência necessária.

De forma mais geral, as regras devem permitir intervenção quando voltadas ao alcance de objetivos de desenvolvimento. Entretanto, os pedidos por aumento de flexibilidade feitos pelos países em desenvolvimento, o que leva ao aumento do espaço político, devem ser equilibrados com o mandamento de não enfraquecer o sistema normativo da OMC.

Caso esse equilíbrio não seja possível, os países mais fortes e poderosos poderiam recorrer a medidas unilaterais, discriminando os países em desenvolvimento mais fracos, privando-os de uma participação mais efetiva no sistema multilateral de comércio. Além disso, poderiam criar mecanismos que limitassem as oportunidades dos países mais fracos de aproveitarem os benefícios da liberalização. Por esses motivos, a flexibilização das normas e a legitimidade do sistema normativo que regula as relações multilaterais de comércio devem passar, entre outras questões, pelo debate do tratamento especial e diferenciado.

\section{O que é o tratamento especial e diferenciado?}

No que diz respeito à construção de uma definição do que é o tratamento especial e diferenciado, deve-se ressaltar que esse instrumento teve como base para a sua criação a promoção de um sistema multilateral mais justo e informado pela necessidade de desenvolvimento. Para tanto, passa a ser imperativo que se busque remontar as percepções adotadas nas discussões que cercaram o tratamento especial e diferenciado ao longo da construção do sistema multilateral de regulamentação do comércio internacional como conhecemos atualmente.

Nesse sentido, pode-se estruturar a concretização do conceito em quatro fases (KECK; LOW, 2005, p. 148). A primeira aborda o período compreendido entre a criação do Acordo Geral de Tarifas e Comércio, em 1948, e a sua evolução até o início da Rodada Tóquio, em 1973. A segunda refere-se à própria Rodada Tóquio, a qual se deu entre 1973 e 1979. 
A terceira tem início ao fim da Rodada Tóquio e vai até o início da Rodada Uruguai (1979-1995), já a quarta e última fase começa ao fim da Rodada Uruguai e estende-se até o presente.

Os princípios basilares do comércio internacional sempre consagraram, sob o princípio "guarda-chuva" da não discriminação, a cláusula da nação mais favorecida e o tratamento nacional, a partir de uma necessidade instrumental de reciprocidade, como mecanismos indispensáveis à liberdade no comércio. Entretanto, se considerados os objetivos de desenvolvimento, deve se ter em mente que esses mecanismos mostram-se realmente indispensáveis, mas jamais imutáveis.

A expansão do capitalismo e o dinamismo imposto pelo comércio internacional trouxeram à tona fraturas na distribuição dos ganhos entre os atores desse processo, em que muitas vezes o respeito a princípios internacionais rígidos e bem delimitados poderia significar a perpetuação de uma situação que se buscava superar, como é o caso dos fenômenos de pobreza e subdesenvolvimento. Esse fato acabou se tornando cada vez mais visível, principalmente após a alteração na lógica comercial internacional do pós-Segunda Guerra Mundial.

Assim, imediatamente após o término do segundo grande conflito mundial do século XX, a problemática do desenvolvimento já se mostrou inserida na agenda internacional. Tal preocupação pode ser verificada a partir do Acordo Geral de Tarifas e Comércio de 1947 (GATT 47), o qual já apresenta um indicativo da necessidade de um tratamento diferenciado. Isso acontece quando, em seu artigo XVIII, permite aos países em desenvolvimento, signatários do acordo, protegerem suas importações e usarem a política doméstica para desenvolver setores em particular, sendo que os Estados-membros ainda poderiam continuar oferecendo acesso especial a países com laços coloniais ou outros países associados, como estabelecido nos anexos do acordo.

Artigo XVIII - Ajustes relativos ao Desenvolvimento Econômico:

1. As Partes Contratantes reconhecem que, no caso de certos ramos de atividade industrial e agrícola, pode ser necessário, para facilitar o seu 
estabelecimento, desenvolvimento ou reconstrução, fazer apelo a um auxílio especial do Estado e que, em certas circunstâncias, a concessão desse auxílio sob a forma de medidas de proteção é justificável. [...]

6. Toda Parte Contratante poderá manter uma medida não discriminatória, incompatível com outras disposições do presente acordo, vigorante em $1^{\circ}$ de setembro de 1947 e que haja sido adotada com o objetivo de criar, desenvolver ou reconstruir determinados ramos da indústria e da agricultura, com a condição de que tal Parte Contratante haja comunicado às demais, o mais tardar até 10 de outubro de 1947, a lista dos produtos aos quais continuará aplicando a medida existente, e a natureza e o fim dessa medida.

Além desse pequeno indicativo de um tratamento especial e diferenciado no GATT 47, tem-se que essa fase embrionária foi dominada pelo debate de acesso a mercados, em particular no que se refere às condições de acesso das exportações dos países em desenvolvimento nos mercados dos países desenvolvidos.

Os teóricos da Comissão Econômica para América Latina e Caribe (Cepal), a partir de uma percepção particular do capitalismo e do comércio internacional, estabeleceram fundamentos doutrinários que culminaram em uma teoria voltada a explicar as bases e as consequências da característica primário-exportadora que levava à deterioração dos termos de troca, ao subdesenvolvimento crônico e ao desenvolvimento tardio historicamente constituído. A contribuição teórica cepalina impulsionou a discussão acerca da manutenção rígida de um arcabouço jurídico fundado em princípios e cláusulas como a não discriminação, a reciprocidade, a cláusula da nação mais favorecida e o tratamento nacional, tendo como fundamento as ordens internacional e doméstica impostas pelas estruturas do pós-Segunda Guerra Mundial.

A Cepal, com suas ideias de substituição das importações, deterioração de termos de troca e integração regional como instrumento de desenvolvimento para Estados com níveis de desenvolvimento diferenciados, lança um desafio, qual seja este, à reestruturação de alguns 
princípios do comércio internacional. Esse desafio tem o objetivo de compatibilizar as diferenças estruturais e históricas dos Estados do Sul, subdesenvolvidos em relação à competitividade dos Estados desenvolvidos do Norte, visando a possibilitar o crescimento de ambos em uma relação justa e transparente de comércio internacional.

O Relatório Haberler², de 1958, também pode ser considerado como uma grande influência dentro do próprio GATT em relação à problemática do desenvolvimento, mesmo que de forma bastante genérica. Tal relatório confirmou as discussões prévias, afirmando que os ganhos com exportações nos países em desenvolvimento eram insuficientes para alcançar as necessidades de desenvolvimento. Ele focou primeiramente nas barreiras impostas pelos países desenvolvidos como uma parte significante do problema, embora também tenha criticado as barreiras ao comércio de alguns países em desenvolvimento.

Baseadas no relatório, as partes contratantes do GATT, na sua $13^{a}$ Sessão Ministerial, estabeleceram três comitês para desenvolver um programa direcionado à expansão do comércio internacional. O Comitê I tinha como objetivo determinar as metas de futuras negociações tarifárias; o Comitê II buscava rever as políticas agrícolas dos Estados-membros do GATT; e o Comitê III visava a identificar questões relativas aos problemas enfrentados pelos países em desenvolvimento.

Deve ser ressaltado que o Comitê III definiu como um dos problemas centrais aos países em desenvolvimento naquele momento as barreiras às exportações mantidas pelos países desenvolvidos, o que levou à consecução de um plano de ação redigido em 1963. Nesse plano, de forma bastante ousada, foi proposto o congelamento de todas as barreiras comerciais impostas pelos países desenvolvidos nos produtos de interesse dos países em desenvolvimento e a remoção de todos os gravames dos produtos tropicais e outros produtos primários, plano esse que acabou

2 Conhecido como Haberler Report, em homenagem ao professor Gottfried Haberler, o qual presidia o painel de economistas indicados para discutir a problemática das exportações e deterioração dos termos de troca no comércio internacional em 1958. 
sendo incorporado aos debates, que tiveram início em 1964, realizados na Rodada Kennedy.

A partir de 1964, iniciou-se uma fase de grande relevância para a problemática do desenvolvimento e a discussão acerca de um tratamento especial e diferenciado, com o nascimento da Conferência das Nações Unidas para o Comércio e o Desenvolvimento (UNCTAD).

A UNCTAD, baseada nas premissas cepalinas, no número crescente de Estados recém-independentes com a descolonização no Caribe, África e Ásia, no novo equilíbrio do poder trazido pela Guerra Fria, e no sucesso dos países em desenvolvimento em colocar os seus problemas no centro das discussões do GATT, atua como elemento de pressão e influenciando diretamente a criação da Parte IV do GATT em 1965. Isso, por sua vez, acabou representando a concretização das críticas aos princípios da reciprocidade e da igualdade absoluta que açambarcavam o comércio internacional até então, como bem ressalta Paulo Roberto de Almeida (1998, p. 159):

para compensar esse desequilíbrio estrutural, desde muito cedo - particularmente a partir dos trabalhos de Raúl Prebish sobre o intercâmbio desigual, no final dos anos 40 - se pensou em introduzir o princípio da não-reciprocidade no GATT, o que não foi, contudo, muito fácil. Foi preciso aguardar a realização, em 1964, da Conferência das Nações Unidas sobre Comércio e Desenvolvimento (UNCTAD), para que a prática do tratamento discriminatório, "a favor" dos países em desenvolvimento, fosse estabelecida como regra válida no comércio internacional e, como tal, fosse ratificada em seguida - embora não como princípio base - pelo GATT. A agenda negociadora internacional aproximava-se, pela primeira vez, dos interesses dos países em desenvolvimento, introduzindo de maneira embrionária os conceitos de tratamento especial e mais favorável que iriam frutificar alguns anos depois.

A Parte IV do Acordo Geral de Tarifas e Comércio, efetivada em 1965, passou a orientar a regulação do sistema multilateral de comércio internacional no que concerne principalmente ao tema desenvolvimento. 
É importante notar que o texto da Parte IV do GATT formaliza princípios e ideais muito explorados pelos teóricos cepalinos. Nessa mesma direção, e baseado nas mesmas premissas, em 1968 é criado o mecanismo do Sistema Geral de Preferências (SGP) ${ }^{3}$.

Essa perspectiva da UNCTAD pode ser facilmente visualizada a partir de seus documentos oficiais, que sempre ressaltaram a necessidade de utilização do comércio internacional como instrumento de redução das desigualdades entre países desenvolvidos e em desenvolvimento.

O comércio internacional é reconhecido como um importante motor de crescimento na economia mundial e globalização. O desafio-chave é maximizar o potencial do comércio de bens, serviços e commodities para os países em desenvolvimento, de modo a torná-los capazes de alcançar o crescimento sustentável, o desenvolvimento e a redução da pobreza. A receita previsível e crescente do comércio pode atenuar substancialmente os constrangimentos de câmbio de moeda estrangeira enfrentados pelos países em desenvolvimento, reduzir a dependência à ajuda estrangeira, e aliviar o fardo da dívida externa. Um desempenho melhor no comércio pode contribuir para elevar os níveis de investimentos externos e estrangeiros, fortalecer e diversificar a base econômica e acentuar a eficiência na alocação de recursos, por meio de uma maior competição. O comércio pode proporcionar um ímpeto importante para o fortalecimento da base científica e tecnológica do país e promover inovações, as quais estão entre os determinantes principais de um conteúdo local maior, intensificando as atividades de valor agregado doméstico e melhorando o retorno sobre os fatores de produção [...].

3 O Sistema Geral de Preferências (SGP) foi idealizado no âmbito da Conferência das Nações Unidas para o Comércio e o Desenvolvimento (UNCTAD), com o objetivo de permitir que mercadorias de países em desenvolvimento pudessem ter um acesso privilegiado aos mercados dos países desenvolvidos, em bases não recíprocas, superando-se, dessa forma, o problema da deterioração dos termos de troca e facilitando o avanço dos países beneficiados nas etapas no processo de desenvolvimento. Por meio do SGP, certos produtos, originários e procedentes de países beneficiários em desenvolvimento e de menor desenvolvimento recebem tratamento tarifário preferencial (redução da tarifa alfandegária) nos mercados dos países outorgantes desse programa.

Revista de Direito Econômico e Socioambiental, Curitiba, v. 3, n. 1, p. 11-42, jan./jun. 2012 
Aumentar os ganhos gerados pelo comércio para os países em desenvolvimento é do interesse dos países desenvolvidos, considerando que o crescimento potencial da demanda interna em alguns países desenvolvidos provavelmente cederá no futuro, refletindo tendências demográficas de longo prazo e o alto grau de saturação do consumo (UNCTAD, 2004, p. 2).

Diante das crescentes exigências dos países em desenvolvimento, muito em razão do nascimento da UNCTAD, que acabou por criar um clima de "concertação" entre os países menos desenvolvidos, alcança-se a cristalização de forma embrionária das demandas de tratamento especial diferenciado no sistema multilateral de comércio.

A Parte IV do GATT, intitulada "Comércio e Desenvolvimento", dá uma nova visibilidade à problemática dos países menos desenvolvidos. Ela cria instrumentos jurídicos que abordam de frente a não discriminação e a reciprocidade, considerando o acesso dos países em desenvolvimento aos mercados dos Estados desenvolvidos e levando em conta o comércio internacional como instrumental de desenvolvimento a partir do tratamento especial e diferenciado ${ }^{4}$.

É importante ressaltar a influência das ideias cepalinas no concernente ao tratamento diferenciado e à elaboração do princípio da não reciprocidade aos Estados em desenvolvimento. Isso pode ser verificado a partir do texto estabelecido no próprio GATT em sua Parte IV, o qual define que "as partes contratantes desenvolvidas não esperam reciprocidade pelos compromissos assumidos por estas em negociações comerciais para reduzir ou remover tarifas e outras barreiras em relação aos países menos desenvolvidos" 5 .

O princípio da não reciprocidade, juntamente com as exceções especiais às políticas de substituição de importações, são geralmente

4 GATT (1965), Parte IV, artigo XXXVI, 1(b): "The export earnings of the less-developed contracting parties can play a vital part in their economic development...".

5 GATT (1965), Parte IV, artigo XXXVI, 8: "the developed contracting parties do not expect reciprocity for commitments made by them in trade negotiations to reduce or remove tariffs and other barriers to the trade of less-developed countries...". 
referidos como "tratamento especial e diferenciado aos países em desenvolvimento". Essa perspectiva, portanto, concretiza as buscas por uma coordenação entre a necessidade de coexistência das políticas de substituição de importações, pela urgência da proteção de alguns setores dos mercados dos países em desenvolvimento e pela abertura do comércio internacional, criando um mecanismo extraordinário em relação ao inicialmente apresentado pelo GATT em 1947, principalmente quando excepciona o princípio basilar da não discriminação.

A Parte IV do GATT, por mais genérica e insuficiente que tenha sido, foi um avanço considerável no debate, pois consistiu no delineamento de três artigos sobre comércio e desenvolvimento, o que para aquele tempo deve ser considerado como um avanço significativo.

Designada para promover o desenvolvimento e os interesses dos países em desenvolvimento no comércio internacional, a Parte IV do GATT, porém, nunca passou de um conjunto de acordos de boas intenções, os quais não galgaram a efetividade necessária a um tratamento especial e diferenciado dentro do grande quadro do comércio e desenvolvimento. Isso acabou gerando insatisfação entre muitos países em desenvolvimento.

Contudo, não se deve subtrair todos os méritos da Parte IV do GATT, pois uma característica muito particular e importante foi a afirmação do princípio da não reciprocidade, estabelecida no artigo XXXVI $-8^{6}$, que pode ser considerado com um marco essencial para o futuro do tratamento especial e diferenciado.

A não reciprocidade deve ser considerada como um conceito bastante abrangente, nunca tendo passado de uma consideração genérica, podendo ser interpretada como um simples compromisso de que no curso das negociações do GATT os países em desenvolvimento não deveriam contribuir de forma inconsistente com o seu desenvolvimento individual e necessidades comerciais e financeiras.

6 "Artigo XXXVI, 8. As Partes contratantes desenvolvidas não esperam reciprocidade pelos compromissos tomados por elas nas negociações comerciais quanto à redução ou remoção dos direitos aduaneiros e de outros obstáculos ao comércio das Partes Contratantes menos desenvolvidas". 
Um grande exemplo instrumental da não reciprocidade encontra-se na sistemática adotada a partir da criação do Sistema Geral de Preferências (SGP), um modelo que reacende as ideias cepalinas quanto à não reciprocidade e ao tratamento especial e diferenciado aos países em desenvolvimento.

Embora não exista uma expressa obrigação legal na Parte IV do GATT, esta abre a possibilidade da concessão de tratamento não recíproco a partir de sistemas externos ao sistema do GATT, os quais acabaram sendo vislumbrados com a criação do Sistema Geral de Preferências (SGP) e também da celebração da Convenção de Lomé7.

O SGP, iniciado sob os auspícios da UNCTAD em 1968, corrobora a concretização do princípio da não reciprocidade previsto na Parte IV do GATT, estabelecendo preferências nos Estados desenvolvidos no que tange a produtos provenientes e originários de Estados em desenvolvimento. Com isso, cria-se uma exceção à Cláusula da Nação Mais Favorecida (artigo I, GATT), vez que promove a concessão de preferências não recíprocas por Estados desenvolvidos aos Estados em desenvolvimento. Tal efetivação não possui qualquer relação formal, entretanto, estão diretamente ligadas por uma tendência inaugurada pelos debates cepalinos.

Em 1971, o GATT autoriza preferências como uma exceção à Cláusula da Nação Mais Favorecida (NMF) por meio de uma waiver. Essas preferências foram justificadas como necessárias ao aumento do acesso a mercados, que seriam mais tarde uma das tônicas das discussões da Rodada Tóquio, e também vistas como a continuidade das preferências advindas de relações coloniais, como previsto em 1947. Tais preferências foram implementadas por países desenvolvidos isolados, e não a partir de uma redução tarifária geral.

7 Uma série de convenções assinadas por países ACP em Lomé (I, II, III e IV), todas com o objetivo de gerar uma coordenação comercial, garantindo a liberdade de acesso ao mercado comunitário de quase todos os produtos dos países ACP e assegurando estabilidade de receitas de exportação para 36 produtos-base. 
Em um segundo momento, com a Rodada Tóquio (1973-1979), a perspectiva do debate é sensivelmente alterada, e o entendimento de que o desenvolvimento poderia ser criado a partir de uma noção doméstica de substituição das importações perde força. A discussão começa a ser direcionada à necessidade de políticas orientadas ao estímulo das exportações, ou seja, a proteção doméstica a partir de barreiras aos produtos importados perde força para uma noção de que o desenvolvimento ocorre com uma ampliação de mercado a partir do acesso ao mercado internacional, o que coloca no centro das discussões questões como subsídios às exportações e acesso a mercados.

É importante frisar que a substituição das importações passa a não ser a melhor alternativa, desde que vislumbram-se suas limitações tendo em consideração o fracasso de algumas políticas direcionadas por essa perspectiva, sendo uma das principais consequências os efeitos distorcidos que a substituição das importações causam às relações comerciais multilaterais. Essa mudança de postura diante do comércio internacional e ao desenvolvimento implicou maior abertura à competição das importações, assim como à remoção de políticas preconceituosas em relação às exportações.

Por sua vez, a Parte IV do GATT, mesmo que de forma tímida, cobria a possibilidade de mudança na trajetória do debate para uma questão mais centrada nas próprias políticas de desenvolvimento dos países em desenvolvimento, assim como no acesso a mercados de suas exportações. Dessa forma, não distante do que podia ser vislumbrado a partir da Parte IV do GATT, a Rodada Tóquio acabou marcada por uma forte ênfase em medidas não tarifárias de comércio, fato esse que distingue a segunda fase da primeira.

Durante a Rodada Tóquio, os países em desenvolvimento limitaram-se a defender interesses que pudessem ser afetados com os acordos sobre medidas não tarifárias e que viessem impor limitações às suas políticas domésticas ligadas às suas necessidades imediatas de desenvolvimento, tal como as reformas administrativas e fiscais. Essa preocupação dos países em desenvolvimento, conjuntamente com a importância dada 
ao tema da não reciprocidade nas negociações de acesso a mercados, levou a três importantes resultados para os países em desenvolvimento e para a consolidação do debate sobre tratamento especial e diferenciado:

a) o estabelecimento pelos países em desenvolvimento de compromissos de acesso a mercados bastante limitados;

b) a adoção de uma prática de codificação com respeito aos novos acordos de medidas não tarifárias, significando que os acordos seriam aplicados somente aos signatários;

c) a imposição de um novo modelo para definir e codificar direitos essenciais e obrigações dos países em desenvolvimento subordinados ao GATT.

Em 1979, logo após a Rodada Tóquio, adota-se a Cláusula de Habilitação ${ }^{8}$ para permitir preferências somente a países em desenvolvimento, incluindo posteriores flexibilizações na aplicação de regras multilaterais, como, por exemplo, no caso da concessão de um tratamento diferenciado e mais favorável em relação às provisões do GATT, concernentes a medidas não tarifárias para países menos desenvolvidos, acordos regionais de comércio entre países em desenvolvimento ${ }^{9}$. Assim, a Cláusula de Habilitação cria o lastro jurídico necessário para o fortalecimento de um sistema de preferências, tal qual o SGP, além do que passa a lastrear também medidas de tratamento especial e diferenciado sob o GATT, acordos regionais e globais de preferências entre países em desenvolvimento e um tratamento especial para países com menor grau de desenvolvimento.

Ainda, a Cláusula de Habilitação reafirmou o princípio da não reciprocidade, primeiramente delineada na Parte IV do GATT, estabelecendo de forma clara que os países em desenvolvimento respeitariam a

8 É essencial salientar que a Cláusula de Habilitação foi criada a partir de uma decisão e não por uma emenda. Decisão de 28 de novembro de 1979 (L/4903). Ver: Cláusula de Habilitação, discutida neste trabalho (GATT, 1979).

9 Esse é o primeiro momento em que, de forma taxativa, se faz uma diferenciação entre países em desenvolvimento e países menos desenvolvidos nas normas multilaterais de comércio do GATT.

Revista de Direito Econômico e Socioambiental, Curitiba, v. 3, n. 1, p. 11-42, jan./jun. 2012 
sua capacidade de contribuir e negociar compromissos, tendo em consideração aqueles acordos que visassem a aumentar o progressivo desenvolvimento das suas economias e melhoria da sua posição comercial.

Como questão central para o presente trabalho, é de importância fundamental salientar que a Cláusula de Habilitação pode ser considerada, também, como o início de uma noção de "graduação" de desenvolvimento, ou seja, uma definição de como determinar quais são os países que teriam acesso a um tratamento especial e diferenciado diante das normas multilaterais de comércio internacional em razão do seu nível de desenvolvimento. Esse mecanismo de determinação do nível de desenvolvimento tem se mostrado atualmente como um grande obstáculo a uma aplicação mais efetiva do tratamento especial e diferenciado, como será verificado no presente trabalho.

O debate pós-Rodada Tóquio foi cercado por percepções diferentes sobre os impactos da Rodada para as futuras negociações de comércio internacional, assim como para a assimilação da posição dos países em desenvolvimento em relação ao sistema multilateral de comércio. Contudo, os assuntos levantados com a Rodada passaram a ser centrais na agenda do tema comércio e desenvolvimento, principalmente no que diz respeito aos impactos positivos e negativos da flexibilização das normas alcançada pela Rodada Tóquio, as necessidades individuais de desenvolvimento dos países-membros do GATT, o apoio do GATT aos países em desenvolvimento na formulação de melhores políticas de comércio e o poder de barganha dos países em desenvolvimento nas negociações multilaterais.

É certo que os debates pós-Rodada Tóquio continuaram simplificando demais a realidade, assim como durante a Rodada, pois falharam em delinear adequadamente as diferenças existentes entre os países em desenvolvimento dentro do sistema, vez que estes possuíam diferentes necessidades de desenvolvimento, portanto, diferentes políticas e objetivos de negociação.

A terceira fase na evolução do tratamento especial e diferenciado é marcada pelas negociações da Rodada Uruguai, a qual é caracterizada 
por uma nova alteração na direção no debate. Isso se dá em razão de um crescimento rápido e de uma grande diversificação nas economias de alguns países em desenvolvimento, particularmente na Ásia, e em algum grau na América Latina, o que deu a eles novas condições de participação no sistema multilateral de comércio, mudando a direção dos seus interesses nas negociações internacionais.

No entanto, mesmo com uma significativa diversificação das economias dos países em desenvolvimento, estes se sentiram em desvantagem pouco antes de entrarem nas negociações da Rodada Uruguai. Isso se deu porque muitos países, em razão da alteração da perspectiva de substituição das importações para uma atuação mais direcionada ao incentivo às exportações, haviam reduzido barreiras às importações antes do início da Rodada sem ao menos usar a retirada dessas proteções como instrumento de negociações e barganha em relação a compromissos de outros países, como é o caso dos países desenvolvidos que começaram a ter mais acesso aos mercados dos países em desenvolvimento.

Assim, um senso de que o próprio sistema necessitava de alterações começou a surgir. Nesse momento, o sistema multilateral de comércio enfrentava o desafio do crescente uso de obstáculos voluntários às exportações como medidas contingenciais de proteção, ao mesmo tempo em que o regionalismo surgia na cena das políticas de comércio internacional de uma forma mais significativa.

Os países em desenvolvimento e desenvolvidos começaram nesse momento a travar batalhas na regulamentação mais específica de algumas áreas, como foi o caso da agricultura e têxteis/vestuário. Também os governos de alguns países desenvolvidos desejaram ver o sistema de comércio internacional englobando novas áreas, particularmente no que diz respeito a investimentos, comércio de serviços e direitos da propriedade intelectual. Nesse mesmo momento, a ideia de que os países em desenvolvimento deveriam assumir maiores níveis de obrigações em relação ao sistema também ganhava espaço, o que levou a um novo embate em relação a uma flexibilização das normas multilaterais de comércio e um tratamento especial e diferenciado. 
Ao fim da Rodada Uruguai em 1995, os países em desenvolvimento haviam assumido um nível de compromissos diante do sistema multilateral sem precedentes. Tal assunção de obrigações por parte dos países em desenvolvimento diante do sistema multilateral de comércio se deve a alguns fatores, como é o caso do single undertaking, o qual passou a regular a forma de adesão dos membros do sistema aos acordos negociados no âmbito multilateral, que estabelecia que a adesão deveria ser feita em bloco e que o Membro que fizesse parte da OMC deveria aceitar todos os acordos realizados no seio desta. O single undertaking por si só já alterou diametralmente a posição dos países em desenvolvimento tendo em vista a mudança na forma de adesão aos acordos se comparado com a Rodada Tóquio, em que existia uma adesão conhecida também como a la carte, ou code approach.

Portanto, somente essa mudança já criou uma grande diferença nos compromissos assumidos pelos países em desenvolvimento em relação ao sistema multilateral de comércio, gerando uma nova necessidade de se discutir a flexibilização das normas diante de um tratamento especial e diferenciado.

Por sua vez, no comércio de mercadorias, a Rodada Uruguai resultou na previsão de que todos os controles de mercadorias passariam a ter que ser específicos, fossem eles tarifários ou não tarifários. Os países em desenvolvimento receberam um tratamento especial e diferenciado quanto aos seus limites tarifários, como foi a caso de produtos não agrícolas (KLEEN; PAGE, 2005). A Rodada Uruguai tentou acabar com todas as diferenciações permanentes, como, por exemplo, o direito de utilizar medidas de salvaguarda continuou existindo e, mesmo com um tratamento diferenciado entre países desenvolvidos e em desenvolvimento, essas diferenciações passaram a ser temporárias.

Contudo, se qualquer alteração fosse feita na Cláusula de Habilitação de 1979, esta continuaria a ser fundamento legal para um tratamento especial e concessão de preferências. Assim, a diferenciação continuava a existir no sistema multilateral, apesar das suas significativas mudanças. As preferências comerciais continuavam a ser permitidas, 
inclusive no que diz respeito à diferenciação para os países menos desenvolvidos ${ }^{10}$. As provisões especiais ao fim da Rodada Uruguai eram uma combinação de permissão a um tratamento especial (preferências, assistência técnica) e isenções a determinadas regras, porém sempre no sentido de acordo de melhores intenções, sem, na realidade, uma força impositiva legal considerável.

A quarta fase começou com um desafio significativo para os países em desenvolvimento, o qual consistia na absorção legal e administrativa dos novos compromissos assumidos na Rodada Uruguai, resultando em profundas modificações nas políticas domésticas. Ainda, em razão dos impactos dos compromissos assumidos diante do sistema multilateral, os países em desenvolvimento passaram a perceber que nem todas as obrigações assumidas na Rodada Uruguai eram consistentes com os interesses econômicos e as prioridades de desenvolvimento. Tal sensação se dava principalmente em razão da percepção de que durante as negociações da Rodada Uruguai os países em desenvolvimento não desfrutaram de grande participação nos assuntos essenciais ao seu desenvolvimento, muito por conta da falta de poder de barganha (moeda de troca).

O debate pós-Rodada Uruguai sobre o tratamento especial e diferenciado, ao contrário do que existia nas fases precedentes, começa a encontrar um rumo mais específico, muito em razão do amadurecimento da discussão acerca do impacto do sistema multilateral no desenvolvimento. Em virtude disso, as discussões passam a ter, como temas centrais, as dificuldades que alguns países em desenvolvimento encontram enquanto tentam aplicar as obrigações assumidas, tendo em consideração o custo, os aspectos administrativos e a necessidade de capital humano para o cumprimento dessas obrigações e, por isso, a necessidade de um tratamento especial e diferenciado.

${ }^{10}$ O que foi reforçado pela decisão de dezembro de 1993 em favor dos países com menor grau de desenvolvimento, a qual incentivava a rápida implementação de cortes tarifários em produtos de interesse dos países em desenvolvimento. 
Outro aspecto refere-se a previsões de vários acordos da OMC que desconsideram a diferenciação dos países em desenvolvimento, assim como a graduação de desenvolvimento. A ausência de elementos claros de diferenciação no conjunto de normas da OMC passa a ser parte da preocupação quanto aos impactos das medidas de tratamento especial e diferenciado. Dessa forma, o debate passa a abordar de forma mais consistente não somente a necessidade de um tratamento especial e diferenciado, mas os impactos do tratamento especial e diferenciado existente no desenvolvimento do sistema multilateral de comércio internacional a partir dos instrumentos de graduação de desenvolvimento e diferenciação.

A UNCTAD, por sua vez, embora atualmente tenha perdido pouco de sua atuação efetiva como foro negociador das relações econômicas internacionais, continua a reafirmar a importância da consolidação do tratamento especial e diferenciado no âmbito da OMC, mesmo que tal tratamento tenha sido muito relativizado desde a criação da UNCTAD e da elaboração da Parte IV do GATT, como pode ser verificado em nota do Secretariado da UNCTAD, a qual:

reafirma que as disposições relativas ao tratamento especial e diferenciado são parte integrante do acordo da OMC e concorda que todas as disposições de tratamento especial e diferenciado deverão ser revisadas do ponto de vista de fortalecê-las e de fazê-las mais precisas, eficientes e operacionais.

[...]

Um tratamento especial e diferenciado de base ampla, não discriminatório e orientado para o desenvolvimento teria de refletir os seguintes elementos-chave: (a) fortalecimento do tratamento e da não discriminação das nações mais favorecidas (NFM) mantendo o princípio da reciprocidade menor para os países em desenvolvimento e o tratamento preferencial, sempre que possível (UNCTAD, 2004, p. 10-11).

Nesse sentido, a discussão ocorreu em diferentes contextos por meio dos últimos anos. Algum progresso foi alcançado ao incluir algumas 
das questões tratadas em Doha ${ }^{11}$, mas alguns elementos dessa discussão permanecem sem a devida apreciação. Em Doha, outra perspectiva foi lançada, qual seja, a da necessidade de tornar as provisões de tratamento especial e diferenciado mais efetivas, como estabelecido na Declaração de Doha ${ }^{12}$, e que pode ser aduzido da leitura do seu parágrafo 44:

44. Nós reafirmamos que as provisões de tratamento especial e diferenciado são parte integrante dos Acordos da OMC. [...] Por conseguinte, acordamos que todas as provisões de tratamento especial e diferenciado deverão ser revisadas com o objetivo de reforçá-las, tornando-as mais precisas, efetivas e operacionais. Assim, nós endossamos o programa de trabalho em tratamento especial e diferenciado criado na Decisão sobre Questões Relativas à Implementação (OMC, 2001).

Ao mesmo tempo em que o parágrafo 44 da Declaração de Doha chama a atenção para uma revisão de todas as provisões relativas ao tratamento especial e diferenciado em busca de fortalecer e torná-lo mais preciso, efetivo e operacional, resta claro que se trata de uma simples declaração de "boas intenções", sem a força legal necessária para estabelecer efetividade às mudanças necessárias. Contudo, além da busca por eficácia e especificidade das provisões de tratamento especial e diferenciado, permanece o problema de como operacionalizar esse mecanismo de tratamento especial e diferenciado tão necessário para o desenvolvimento, ao mesmo tempo em que se reforça a eficácia do conjunto de normas que cercam o sistema multilateral de comércio, evitando assim as consequências distorcidas e excludentes que podem advir da diferenciação, sem esquecer da dificuldade existente na determinação de como diferenciar países com necessidades tão distintas e níveis de desenvolvimento tão peculiares.

Como parâmetro teórico, a Cepal e a teoria da dependência inseriram na realidade do comércio internacional uma perspectiva que, no

${ }^{11}$ A rodada Doha teve início em 9 de novembro de 2001 em Doha, Qatar, como a IV Conferência Ministerial da OMC, em que foi lançada uma nova rodada de negociações multilaterais sob a supervisão do Comitê de Negociações Comerciais subordinado ao Conselho Geral da OMC.

12 Adotada em 14 de novembro de 2001. 
mínimo, sugeriu a necessidade de discussão dos impactos do comércio internacional com relação aos países menos desenvolvidos. A análise cepalina, informada por um entendimento do subdesenvolvimento histórico sob a égide da expansão do sistema capitalista, acabou gerando uma série de considerações que não foi nem poderia ser marginalizada, quando da análise da problemática do livre-comércio e da integração regional.

Essas abordagens conseguem apresentar argumentos que possibilitam a inserção do debate do desenvolvimento em uma realidade informada pela revisão de conceitos basilares do comércio internacional, principalmente tendo em consideração um tratamento especial e diferenciado aos países menos desenvolvidos e em desenvolvimento utilizando o comércio internacional como instrumento passível de gerar desenvolvimento. No entanto, é importante salientar que tal desenvolvimento somente poderá acontecer a partir da percepção das diferenças econômico-estruturais historicamente informadas entre Norte e Sul, e até mesmo entre o Sul e o Sul.

\section{Referências}

ALMEIDA, P. R. et al.: uma perspectiva comparada sobre a macroestrutura política das relações econômicas internacionais. In: CASELLA, P. B.; MERCADANTE, A. A. (Coord.). Guerra comercial ou integração mundial pelo comércio?: a OMC e o Brasil. São Paulo: LTr, 1998. p. 149-198.

BROWN, A.; STERN, R. Concepts of fairness in the global trading system. Pacifica Economic Review, v. 12, n. 3, p. 295-305, 2007.

CONFERÊNCIA DAS NAÇÕES UNIDAS PARA O COMÉRCIO E O DESENVOLVIMENTO - UNCTAD. Assegurando ganhos de desenvolvimento a partir do sistema comercial internacional e das negociações de comércio. 2004. Disponível em: <http://unctad.org/pt/docs/td397_pt.pdf>. Acesso em: 27 dez. 2012. 
ORGANIZACIÓN MUNDIAL DEL COMERCIO - OMC. Doha, 2001: Declaración Ministerial. Disponível em: <http://www.wto.org/spanish/thewto_s/minist_s/ min01_s/mindecl_s.htm>. Acesso em: 27 dez. 2011.

GENERAL AGREEMENT ON TARIFFS AND TRADE - GATT. Amending the general agreement on tariffs and trade to introduce a part IV on trade and development. 1965. Livro. 2355, p. 2-4. Disponível em: <http://www.wto. org/gatt_docs/English/SULPDF/90780015.pdf>. Acesso em: 20 dez. 2011.

GENERAL AGREEMENT ON TARIFFS AND TRADE - GATT. Decision of 28 November 1979 (L/4903). 1979. Disponível em: <http://www.wto.org/english/docs_e/legal_e/enabling1979_e.htm>. Acesso em: 20 dez. 2011.

ISMAIL, F. Mainstreaming economic development in the trading system. In: EVENETT, S. J.; HOEKMAN, B. M. Economic development and multilateral trade cooperation. Oxford: World Bank and Palgrave Macmillan, 2005. p. 207-121. KECK, A.; LOW, P. Special and differential treatment in the WTO: why, when and how? In: EVENETT, S. J.; HOEKMAN, B. M. Economic development and multilateral trade cooperation. Washington, D.C.: World Bank and Palgrave Macmillan, 2005. p. 147-188.

KLEEN, P.; PAGE, S. Special and differential treatment of developing countries in the WTO. Stockholm: Ministry of Foreign Affairs, 2005.

NASSER, R. A. A OMC e os países em desenvolvimento. São Paulo: Aduaneiras, 2003. SEN, A. Desenvolvimento como liberdade. São Paulo: Companhia das Letras, 2000. STIGLITZ, J.; CHARLTON, A. A development round of trade negotiations? The World Economy, v. 28, n. 3, p. 293-312, 2005.

Recebido: 02/05/2012

Received: 05/02/2012

Aprovado: 12/07/2012

Approved: 07/12/2012 